\title{
La corrupción inarmónica ${ }^{1}$
}

\author{
Ibiza Melián \\ UNIVERSIDAD REY JUAN CARLOS, MADRID, ESPAÑA \\ ibizamelian@gmail.com
}

Resumen: La presente nota analiza, desde una perspectiva axiológica, por qué los índices de percepción de la corrupción política y administrativa son mayores en el sur que en el norte de Europa. Así como en Latinoamérica, heredera cultural de España y Portugal. La cuestión específica que se investiga es cómo la religión y la filosofía han modelado dos visiones diferentes de entender la esencia humana en el Occidente cristiano. Con especial énfasis en el estudio del caso de España. El método de investigación empleado es cualitativo y parte de un análisis de contenido de multiplicidad de textos ortodoxos, además de otros calificados en su momento de heréticos. Heterodoxia que arranca en el Antiguo Egipto y que tiene como figura principal al faraón Akenatón, el vertebrador del primer monoteísmo. Pensamiento que se desarrolla a partir de la Maat, la armonía que ha de dominar cada acto. Elemento difuminado en la ortodoxia católica, de manera que allí donde se impuso terminó por derivar en una corrupción inarmónica. Cristianismo que se dividió en uno católico, donde lo importante es el colectivo, y otro protestante, en el que prima el individuo. Países protestantes preocupados por preservar la separación de poderes, mientras que los católicos abogaron por el «rey-filósofo».

Palabras clave: corrupción, separación de poderes, derechos fundamentales, política, religión, filosofía

Abstract: This note analyzes, from an axiological perspective, why the perception rates of political and administrative corruption are higher in the South than in Northern Europe, as well as in Latin America, which is an inheriting population of the culture of Spain and Portugal. The specific question to be investigated is how the religion and the philosophy have shaped two different visions to understand the human essence of Western Christianity, with specific emphasis on the study of Spain. The research method used is qualitative, it is based on an analysis of the content of the multiplicity of orthodox texts, besides others qualified in its belief of heretical doctrines. Heterodoxy started in Ancient Egypt and it had as its principal figure to the Pharaoh Akenatón, who created the first monotheism. Thoughts based on the Maat, the harmony that has to dominate every act. This element was forgotten within the catholic orthodoxy and it caused an inharmonious corruption. Christianity was divided into Catholic, where the most important message is the collective, and Protestant, where the individual prevails. Protestant countries worried about preserving the separation of power, whereas the Catholics pleaded for the philosopher King.

Keywords: corruption, separation of powers, fundamental rights, politics, religion, philosophy

1. Se compartió un avance de esta investigación en el XIII Congreso de la Asociación Española de Ciencia Política y de la Administración (AECPA), celebrado en la Universidad de Santiago de Compostela, entre los días 20 y 22 de septiembre de 2017. 


\section{Introducción}

ño tras año los Índices de Percepción de la Corrupción, llevados a cabo por Transparencia Internacional, muestran tasas más elevadas en el sur que en el norte de Europa. De manera que la presente investigación trata de responder a la pregunta de por qué se produce esa diferenciación. La hipótesis que se pretende validar es que los países católicos — Portugal, España, Italia y Grecia, en su fórmula cristiana de Iglesia Ortodoxa- ostentan niveles de corrupción más elevados que los protestantes. Y por ende Latinoamérica, heredera cultural de España y Portugal. Luego, la variable dependiente u objeto de estudio es la corrupción política y administrativa. Si bien, la independiente o explicativa se centraría en el factor religioso y filosófico.

Entendido el concepto corrupción como el uso por parte de las autoridades o funcionarios públicos de su cargo, para favorecerse económicamente o de otra forma a sí mismo o a otros. Por su parte, el término religión hace referencia, según la definición esbozada por la Real Academia de la Lengua, al «conjunto de creencias o dogmas acerca de la divinidad, de sentimientos de veneración y temor hacia ella, de normas morales para la conducta individual y social y de prácticas rituales, principalmente la oración y el sacrificio para darle culto». La explicación de filosofía, también conforme a lo manifestado por la misma institución, sería la relación «de saberes que busca establecer, de manera racional, los principios más generales que organizan y orientan el conocimiento de la realidad, así como el sentido del obrar humano». Y, por último, el vocablo esotérico, utilizado en la investigación, alude a la sapiencia filosófica o psicológica que permite al individuo el máximo desarrollo intelectivo. Saber transmitido a un grupo reducido mayormente a través de un proceso iniciático.

Desviaciones del sistema que algunos investigadores ya han apuntado que es aparentemente menor en aquellas naciones cuya religión mayoritaria practicada es más intimista (Treisman, 2000). Factores culturales e históricos que se intuye que predispondrían al sujeto a poder perpetrar mayores acciones corruptas, conforme a lo apuntado por ciertos trabajos cuantitativos (Meier y Holbrook, 1992).

Una investigación de relevancia teórica y sustantiva, al abordar un asunto crucial para nuestra sociedad. De su óptimo resultado depende que obtengamos una mayor comprensión y por ende mejores soluciones para erradicar una lacra que corroe los cimientos del Estado español.

\section{Método}

El método de investigación empleado es cualitativo. Basado en el análisis de contenido de multiplicidad de textos ortodoxos, además de otros calificados en su 
momento de heréticos. Como de los fundamentos de distintas corrientes místicas, religiosas, filosóficas y de grupos hoy denominados «discretos».

Se parte del pensamiento del Antiguo Egipto y su posterior reinterpretación por el mundo griego. Los pitagóricos y las teorías metafísicas de Platón. La influencia egipcia y persa en el judaísmo, así como su desarrollo por parte del cristianismo. La cábala y la mística cristiana. El hermetismo y la labor divulgativa de Marsilio Ficino. «El iluminismo rosacruz» (Yates, 2008), la masonería y el martinismo.

De igual modo, se analiza la idea del gobierno de los filósofos subyacente en Platón. Aplicada por José Ortega y Gasset como «minoría selecta» y su trágica derivación en la figura del «cirujano de hierro» español (Costa, 1902). Gobernante utópico que se contrastará con la perspectiva del egoísmo de Ayn Rand, la «sociedad abierta» de Popper o la Teoría de la Elección Pública de Buchanan.

Con todo ello se persigue dejar entrever que la esencia humana es vulnerable, por lo que de nada sirve plantear propuestas para un ser ideal que en realidad no existe y nunca existirá. Individuos que se mueven siempre en busca de su propio beneficio y terminan por interpretar la triste partitura de la corrupción inarmónica.

\section{Resultados}

\subsection{Egipto, cuna del nacimiento del pensamiento occidental}

Las raíces del pensamiento occidental sobre la explicación de la creación del Universo y de la situación del hombre en el mismo se remontan al Antiguo Egipto. Ancestral civilización que perduró durante tres mil años. Especialmente a la etapa regida por Akenatón. Faraón que exhortaba a sus súbditos a luchar contra la idolatría. Idolatría que se materializa al conferir a una persona, grupo u objeto poder sobre el individuo. Reinado caracterizado por la imposición del monoteísmo de Atón, frente al henoteísmo precedente. Un dios único que otorgaba su bendición a todos los seres por igual. Un mensaje de amor, paz, igualdad y bondad que provocó que Akenatón fuera tachado de «hereje» (Dulitzky, 2011).

Empero, no solo el monoteísmo impulsado por Akenatón puso una vital piedra en la construcción del pensamiento filosófico de Occidente, sino también el profundo amor hacia el conocimiento profesado por los egipcios. Sabiduría a la que aspiraban llegar mediante la práctica espiritual y en base al estudio de múltiples símbolos y mitos que les servían de guía. Saber restringido a los magos del Estado egipcio y que obtenían gracias a la intuición, al conectar con lo más recóndito del ser. Luego de pasar por un gradual periplo iniciático. Se buscaba por tanto llegar a la supuesta verdad por medio del acceso a nuestra parte trascendental y no a la racional. Radicada en el interior de cada persona y no en el exterior. 
Los iniciados estimaban que el ser humano estaba compuesto de distintas partes. $\mathrm{Y}$ una de las principales era el $\mathrm{Ka}$, energía vital. Cuyo flujo implicaba que el sujeto mantuviera un honesto comportamiento, que le impedía hablar mal de nadie, calumniar. Ya que, en caso contrario, al interrumpir su armonía, la canalización no prosperaba (Piulats Riu, 2010). Otro componente primordial del individuo para los egipcios era el $B a$, comparable con el vocablo empleado en Occidente como alma. Y el $A h$, que convertía al iniciado en un ente luminoso, para ser mago se mostraba imprescindible su pleno desarrollo (Martín Valentín, 2002).

Ergo, el prototipo de hombre sabio en Egipto era aquel que sabía aplicar su energía vital, $K a$, de forma armónica. Es decir, en concordancia con la Maat. De tal manera que le permitiese cultivar su alma, $B a$. Y por ende lo abocara a obtener la iluminación, $A h$ (Piulats Riu, 2010). Donde se deja entrever la concepción tricotomista del individuo. Persona dividida en cuerpo, alma y espíritu. Alma que es equiparable a la mente, a la que tradicionalmente se le atribuyeron las facultades propias del intelecto: la «imaginación», la «memoria»y las «emociones» (Punset, 2006).

Proceso de unificación que escenificaban por medio del ternario Osiris-IsisHorus: muerte, regeneración y resurrección. La bajada a lo más recóndito del ser para, tras un proceso de autoconocimiento, retornar renacido. Osiris fallece en su vertiente material y se une con su parte divina personificada por Isis, para terminar por converger en la unidad espiritual reproducida por Horus. Ritual iniciático con el que accedían al estado de iluminación, Ah (Piulats Riu, 2010).

Por su parte, Thot era considerado por los egipcios como el dios de la palabra mágica, divinidad de la escritura y la sabiduría. Cuya doctrina se condensaba en lo que denominaban Heka, «poder mágico». Y es que en el Antiguo Egipto magia y religión iban de la mano y la una no se entendía sin la otra. Por eso los magos del Estado eran los sacerdotes. Quienes para hacer realidad en el plano físico lo pensado recurrían a la pronunciación de fórmulas mágicas. El «Verbo Creador» del que surgió todo, luego de ser imaginado. No obstante, dicha concreción debía respetar ineludiblemente la armonía de la naturaleza. Por consiguiente, Thot sería el eterno compañero de la diosa Maat (Martín Valentín, 2002). Deidad que encarna el orden que debe regir en el mundo terrenal y en el celestial, la justicia y la verdad, «patrona de los jueces» (Castel, 2001: 243).

Además, el componente del ritual iniciático egipcio exigía complementarse con otros dos elementos. Con el fin de que el individuo lograra un estado de conciencia superior y se convirtiese en un iluminado, $A h$, o sabio. El primero de ellos era el estudio de la escritura. Mientras que el segundo consistía en aprender a utilizar el Heka. Las tres vías iban intrínsecamente unidas. 
Así pues, el elemento esencial de la religiosidad egipcia era el aspecto éticomoral. Volcados en el ser y no en el parecer. Conscientes de la necesidad de hacer coordinar pensamiento, palabra y acto. Su comportamiento debía estar en armonía con la diosa Maat, que era la que establecía el equilibrio.

Ergo, el romper la conexión energética con el resto de criaturas traía siempre consecuencias negativas (Piulats Riu, 2010). Conexión armónica con su entorno que se reproduce en los chamanes. Capaces de devolver el equilibrio, la sanación, a lo desequilibrado, enfermo. Para quienes el aspecto ético-moral era también sustancial (Almendro, 2010).

\subsection{El judaísmo y su doctrina mística, la cábala}

Si a lo expuesto se añade que tanto la religión de Atón como su heredera, el judaísmo antiguo, negaban cualquier tipo de vida tras la muerte (Freud, 1991), se comprende mejor la importancia que daban a la materia. En este sentido la cábala, insistirá en el esfuerzo que debe emprender la persona por espiritualizarla (Saban, 2016) al objeto de ser conscientes del aquí y ahora. Conciencia que faculta al sujeto para discernir entre el Bien y el Mal. Comportamiento que ha de estar regido perennemente por el principio de la Maat, la perfecta armonía que debe gobernar cada acto. Porque los cabalistas defienden que el ser humano fue creado por Dios en la dimensión física, por lo que no se puede renunciar a las necesidades propias de este estado. Lo contrario sería ir contra la propia naturaleza del individuo (Saban, 2012). De lo que se desprende igualmente que los judíos aceptaran el interés en los préstamos, requerido para que el sujeto pudiera progresar económicamente.

Con posterioridad los judíos entraron en contacto con los persas (Finkelstein y Silberman, 2003), lo que hizo que asumieran determinados conceptos de su teología, el zoroastrismo. Entre cuyos axiomas sobresale asimismo la obligación de coordinar pensamiento, palabra y acto. Del zoroastrismo extrajeron la creencia de la «resurrección de los muertos». La diferenciación entre «el Bien y el Mal», divinidades que buscaban hacerse con el control terrenal. O la idea del juicio final (Piñero, 2016), con una otorgación de premios y castigos. También la fe en ángeles y demonios, así como en la existencia de un cielo y un infierno (Suárez Córdoba, 2015). Después el pueblo de Moisés cayó bajo el dominio griego (Finkelstein y Silberman, 2003).

La línea mística del judaísmo es la cábala. Corriente que promulga que el verdadero Mesías siempre es uno mismo, dado que conferir poder a otros supondría idolatría. Por consiguiente, la mejora colectiva pasa indefectiblemente por la individual. Exclusivamente desde el perfeccionamiento propio se puede contribuir a la reparación del mundo, Tikun Olam. Puesto que el camino a la divinidad es directo y no requiere de intermediario alguno. 
Defensores a ultranza del librepensamiento, la duda constante que ha de predominar en la persona. Debido a que exclusivamente la curiosidad y el cuestionamiento permanente posibilitan el progreso. Porque el ser humano siempre será un eterno aprendiz, el talmid jajam, «aprendiz de sabio». De manera que ha de mostrar continuamente su humildad. Por lo que la soberbia o el orgullo es valorado como una transgresión. Cabalistas contrarios a todo tipo de dogmatismo, al caer en la cuenta de sus limitaciones ante el saber infinito.

Hay que tener en cuenta que el término kabbalah se aproxima bastante a la unión de los tres elementos primordiales que los egipcios creían que componían el ser humano. La energía vital del $\mathrm{Ka}$. El $\mathrm{Ba}$, equiparable al alma. Y el $\mathrm{Ah}$, que convertía al iniciado en un ente luminoso, poseedor del conocimiento superior. Concepción tricotomista de cuerpo, alma y espíritu. Partes que los cabalistas designan con los vocablos de Néfesh, Rúaj y Neshamá.

Lo mismo que en el Antiguo Egipto, la cábala aboga por mantener la armonía, la Maat, entre las distintas fuentes energéticas que conforman el cuerpo humano. Y que la mística judía representa por medio de la imagen alegórica del Árbol de la Vida. Compuesto por diez dimensiones o sefirot, conectadas entre sí por veintidós canales o netivot. Es por ello que la enfermedad se manifiesta cuando se desequilibra alguna dimensión energética o sefirá.

Las tres sefirot superiores, o triada del intelecto, son: Keter, Jojmá y Biná. La intuición (Jojmá) es lo que antiguamente se denominaba profecía y que se podría relacionar con el hemisferio derecho del cerebro. Y por otro lado estaría la razón (Biná), que se asimilaría al hemisferio izquierdo del cerebro. El conocimiento (Daat) surge de la combinación de ambas. La dimensión más cercana a la divinidad es la corona (Keter), que abarca tanto la intuición como la razón. Es decir, es la encargada de que el intelecto utilice ambos hemisferios cerebrales, el derecho y el izquierdo. Una vez más se apunta, al igual que lo hicieran los egipcios, que para llegar a Dios, al Bien, al Uno, al Todo, al Absoluto, a la Primera Causa, a la fuente primigenia, al Gran Arquitecto del Universo (G..A..D..U..) para los masones o al Ein Sof en la cábala, se ha de seguir la senda del intelecto. Porque para los cabalistas el alma se sitúa en el cerebro. Hoy la ciencia asegura que el pensamiento «h-creativo» surge precisamente de la combinación del hemisferio derecho del cerebro con el izquierdo.

Así que la conversión en el ser iluminado de los egipcios, Ah, la Devekut en la cábala, se produciría en la consciencia ketérica, tras combinar la sefirá de Biná con la Jojmá y adquirir el Daat. Cuando la persona encuentra a su Mesías interno, o sea, lo inicialmente fragmentado se ha unificado. Empero, la combinación de las sefirot debe ser armónica, para que no irrumpa una klipá, defecto. Donde la klipá de la Biná, la razón, sería una demasía de dogmatismo que puede llevar al fanatismo (Saban, 2016). 
Lo mismo que los egipcios, los judíos confieren a la escritura un valor crucial para poder expandir la conciencia. Por lo que las tasas de alfabetización dentro del judaísmo, desde sus comienzos, han sido bastante altas (Piñero, 2008). Y es que para ser un buen seguidor de la fe se tiene que saber leer y escribir.

\subsection{El pensamiento helénico}

Fueron los pensadores griegos los encargados de recoger el testigo de los sabios egipcios. Intelectuales que se autodenominaron filósofos, los eternos aspirantes a conseguir la sabiduría. Vocablo acuñado por Pitágoras para diferenciarse de los sabios egipcios.

Por consiguiente, los griegos consideraban primordial para su aprendizaje viajar a Egipto. Peregrinaje que les permitiría conocerse a sí mismos. Se tiene constancia, entre otros, de las estancias de Pitágoras y Platón. Quienes no solo estudiaron su escritura, sino también fueron iniciados en los ritos mistéricos. Abogaron asimismo por la cultura del esfuerzo y por mantener un elevado código ético. Pitágoras transmitió este saber esotérico a los matematikoi. Aseguraba que podía curar mediante la música, que al fin y al cabo era armonía, la Maat egipcia. Vibración armónica que generaba la «música de las esferas».

Platón enseñaba esta sapiencia en sus cursos de «Acerca del Bien» (Piulats Riu, 2010). Autor del Timeo, obra que tuvo una gran influencia sobre los Padres de la Iglesia y que era la síntesis del pensamiento pitagórico. El Timeo relata la creación del «Alma del Mundo» por parte del Demiurgo, situado en una posición de subordinación respecto a la Idea del Bien que se ubica en la cúspide. De esta manera Platón escenificaba el distanciamiento entre lo material, concreción encargada al Demiurgo, y lo espiritual representado por la Idea del Bien. Planteamiento que inspiró al cristianismo paulino. Por lo que san Pablo equiparó el Demiurgo a Jesús, que serían las ideas secundarias, y la Idea suprema del Bien a Dios (Piñero, 2015).

Pues para Platón existían unas ideas que podían ser asimiladas exclusivamente mediante «la parte más elevada del alma», la inteligencia última, el espíritu. Ideas a las que se accedía escalonadamente, desde la base hasta la cúspide. Lo que se asemeja a cualquier proceso de iniciación mistérica. En cuyo vértice estaría la «Idea del Bien». El lugar al que todo iniciado ha de retornar para lograr el conocimiento pleno, la sabiduría. Y justo debajo de este aparecería el Dos, la dualidad.

El paso de las sombras a la luz divina nada más que se muestra factible para los filósofos. Quienes consiguen llegar a lo Bello, al Bien, a través del Amor. El filósofo es pues aquel que ha dejado atrás su parte material para que prevalezca la espiritual (Reale y Antiseri, 1995). El que como en el rito egipcio de Osiris ha muerto en su 
vida profana para renacer en otra consagrada al conocimiento que adquirirá a través de la iniciación (Daza, 2009). Aquel que dedica su vida a la virtud y el conocimiento.

Ergo, el filósofo es el responsable de instaurar el Bien en la sociedad, de crear la sociedad platónica. No obstante, antes ha de empezar por él mismo. Porque la Teoría de las Ideas de Platón se tiene que poner en relación con la de la reminiscencia, también elaborada por él. Insertada en toda corriente mística. Y cuyo germen nace en el Antiguo Egipto y se aprecia en los chamanes. Para Platón existe un saber inserto en el alma y que el individuo ha de tratar de revelar a través de la introspección. Lo mismo afirman los cabalistas, conocimiento al que llaman Daat. Mientras que los alquimistas lo denominan la piedra filosofal. Para quienes la verdad se encuentra dentro de uno mismo (Reale y Antiseri, 1995) y que los gnósticos calificaron como gnosis. Carácter intimista que se imprimió en las religiones que de estas creencias bebieron, excepto en la colectiva católica.

De igual modo Pitágoras se interesó por la política. Para pergeñar su modelo ideal se basó en la teocracia egipcia, gobernada por una élite de sabios sacerdotes dirigidos por el faraón. Quienes preservaban que se mantuviera en todo momento el orden armónico, Maat. Arquetipo en el que se apoyó posteriormente Platón para esbozar el gobierno de los filósofos (Piulats Riu, 2010). De ahí que ambos consideraran el estudio de la música, que al fin y al cabo es armonía, como disciplina imprescindible dentro del aprendizaje de la política (Gil, 2004). Concepción de la que mucho después derivó la «minoría selecta» de José Ortega y Gasset o el mito del «cirujano de hierro» tan ansiado en España. Élite gobernante reflejada igualmente durante los prolegómenos del siglo XX en el enigmático libro de Joseph Alexandre Saint-Yves D’Alveydre, El Arqueómetro, manual de consulta imprescindible para el esoterismo occidental. Tampoco hay que olvidar que el propósito último de la masonería es modelar personas con amplios conocimientos, capaces de revertirlos en la sociedad al objeto de contribuir a su progreso. Máxima que defienden también los martinistas, grupo que surge en la Francia del siglo XVIII y que tiene en Louis Claude de Saint Martin su figura clave. Orden que mantiene fuertes lazos con el rosacrucismo.

En un principio Platón abogó por la figura del «rey-filósofo» que regiría la ciudad ideal, en base a la Justicia y el Bien. Movido no por mandar, sino por servir a los demás. Obligado a mostrar el Bien al resto. Utopía que recogió inicialmente en su obra Gorgias y desarrolló en La República, texto de madurez. En cambio, al final de sus días abandonó esta teoría, tras sinsabores particulares y después de sufrir Grecia primero una dictadura oligárquica y luego una democracia populista. Ahora bien, seguía defendiendo que la formación armónica del ser humano conduciría al desarrollo social. Aunque para lograr una sociedad justa entendía que era mejor supe- 
ditarla a la instauración de buenas leyes y no al arbitrio de encontrar al gobernante perfecto. Normas básicas escritas que rijan para todos. Tal como describe en Leyes, obra de vejez y última. Donde los filósofos ya no gobernarían, sino que serían los que elaborarían las leyes (Reale y Antiseri, 1995). Había pasado de la concepción de lo que el hombre debería ser a lo que en realidad es. De la legitimidad carismática a la legitimidad racional, fundamentada en las normas que la sociedad se haya dado, teoría planteada por el sociólogo alemán Max Weber (Deusdad Ayala, 2001).

Lamentablemente Roma adoptó la concepción idílica de gobierno de La República de Platón y no la realista de Leyes. Y fue esta idea de ciudad utópica regida por prohombres, y no la de aquella otra liderada por rectos principios, la que se asimiló en el Medievo y configuró Occidente (Turull Rubinat, 2008). Si bien, la Biblia desde el comienzo ya avisaba de la tendencia de todo gobernante a ejercer su poder de manera despótica (1 Samuel 8, 10-18).

Esa quimera de encontrar al gobernante ideal será desarrollada ya en el siglo XX por Karl Popper, en su obra La sociedad abierta y sus enemigos. También abordará esta cuestión la Escuela de la Opción Pública (Public Choice). Abanderada por James M. Buchanan, Premio Nobel de Economía en 1986. Debido a que lo lógico "sería establecer normas claras que, pase lo que pase y ostente quien ostente el bastón de mando, haga muy difícil transgredir la legalidad vigente» (Melián, 2015: 89-90). En la línea platónica de Leyes en 1983 Buchanan afirmaría que para mejorar la democracia se ha de incidir en las reglas del juego y no en los jugadores (Álvarez-Rendueles, 2014).

Y es precisamente este matiz último el que ha sido obviado en el sur de Europa. Donde, por ejemplo, en España se continúa clamando por el «rey-filósofo», es decir, el nefasto «cirujano de hierro» patrio. Si a esto se une que el componente ético de la armonía y la teoría del conocimiento interior tampoco se cultivó, ayuda a comprender los desajustes entre el sur y el norte de Europa, en cuanto a la corrupción se refiere. Y al haber arrebatado al sur europeo la vertiente simbólica, quedó huérfana de una parte del conocimiento.

Cabe citar igualmente la especial importancia que tuvo la ciudad griega de Alejandría, fundada por Alejandro Magno. Radicada en el norte de Egipto. Lugar en el que se fusionaron la cultura egipcia con la helénica y ulteriormente con la romana, a lo que hay que agregar la impronta judeocristiana. Localidad en la que se pergeñó el Corpus Hermeticum, interpretación griega de los míticos manuscritos del dios egipcio Thot y que los alejandrinos atribuyen al arquetipo de Hermes Trismegisto (Pérez Pariente, 2016). Idealizado como «el primer alquimista». Sapiencia con tintes platónicos y gnósticos (Priesner y Figala, K. 2001). Y que derivó en lo que se conoce como hermetismo, doctrina definida como «religión de la mente» (Ramos Jurado, 2007: 159). 
Después serían los árabes, - tras conquistar Egipto en torno al 640- los que rescatarían esta sabiduría y la introducirían en Europa a través de la península ibérica «en el siglo VIII». Libros que se traducirían del árabe al latín, especialmente desde el siglo XII en la «Escuela de Traductores de Toledo». Alquimia, entonces, con reminiscencias egipcias, herméticas y enriquecida por el pensamiento árabe (Pérez Pariente, 2016). Tratados alquímicos que se expandieron por la Europa cristiana gracias a la peregrinación a Compostela. Tras el hallazgo en el siglo IX del cuerpo atribuido al apóstol Santiago (Rebisse, 2015).

Por su parte Marsilio Ficino, ya en el Renacimiento, pasó estos textos del griego al latín. En su academia florentina recuperó la «prisca theologia». Compuesta por los axiomas persas de Zoroastro, por las enseñanzas egipcias de Hermes Trismegisto, enriquecida por los pitagóricos, pero por último perfeccionada por Platón (Ludueña Romandini, 2006).

Asimismo, Filón de Alejandría fue un filósofo griego cuyo pensamiento tuvo una gran trascendencia en el cristianismo. Profundo conocedor de la cultura helénica, aunque era «judío practicante» (Albar et al., 1995). Buscaba relacionar la filosofía griega con la teología judía. Como fue el intento de enlazar el Timeo de Platón con el Génisis bíblico (Oñate Zubía y Zamora Calvo, 2013).

Filón puso el énfasis en el componente moral y, conforme a su propio testimonio, en «vivir con todo el ser para Dios y no para uno mismo» (Reale y Antiseri, 1995). Aparece ya, por tanto, el rasgo distintivo que va a separar a las corrientes religiosas individualistas de la colectivista católica. La preeminencia de la dedicación a Dios por encima del mundo material, el que se muestra de por sí como malo, opresor de la vida espiritual. En contraposición a la mística judía que ve imprescindible la materia e impone únicamente la necesidad de espiritualizarla. Ideas estas que asumirán con posterioridad los protestantes y por ende el liberalismo.

La premisa de la exigencia de espiritualizar la materia fue aplicada por los templarios en la Edad Media, precursores de la banca moderna. Y se reflejó en el calvinismo, doctrina instaurada por los Padres Peregrinos en Estados Unidos. Visión plasmada por Weber en su obra La ética protestante y el espíritu del capitalismo.

Teoría individual que desarrolló ampliamente la filósofa y escritora Ayn Rand. Nacionalizada estadounidense; pero nacida en el Imperio ruso en el seno de una familia judía. Quien escribió La virtud del egoísmo. Donde razonó que la palabra egoísmo no conlleva en sí misma una connotación negativa, sino que se refiere a la atención a las inquietudes propias. Y es que, puesto que la naturaleza no provee directamente al sujeto de recursos para mantenerse, ha de ser él mismo quien se los procure para poder subsistir. Lo que en sí no puede ser calificado como malo. De manera que cualquier ideología que le niegue al ser humano esta facultad atentaría contra la vida misma (Rand, 2006). 
Por otro lado, tanto Filón como los cristianos identificaron a la Idea suprema del Bien con Dios. Ergo, el sabio ya no es aquel en el que prima la capacidad intelectiva, el que ama a la Sabiduría. Sino que la razón es relegada por una figura externa al individuo, Dios. De él proviene todo. Condiciona la existencia del individuo y lo lleva hasta la iluminación, siempre que respete las normas que ha establecido (Piñero, 2016).

A todo ello hay que sumar que, tras hacerse el cristianismo con el control hegemónico del Imperio romano, se prohibió la difusión de las enseñanzas filosóficas. Aparte de que los pensadores cristianos escolásticos medievales asumieron las tesis de Aristóteles y no las de Platón. Escolásticos entre los que destacó santo Tomás de Aquino, tomismo que rige todavía hoy la doctrina de la "Gran Iglesia». El ideario platónico y el neoplatónico de sus sucesores tuvo que esperar para ser rescatado hasta el Renacimiento, gracias a las traducciones de Marsilio Ficino (Ramos Jurado, 2007).

Renacimiento en el que se ensalzó la libertad, abanderada por la burguesía. Ansias de libertad que sintetizó Pico della Mirandola, discípulo de Marsilio Ficino, en su famoso «discurso sobre la dignidad del hombre» (Ortega, 2016). Tesis que provocaron su excomunión. Proclama en la que entrelazó los textos sagrados con la doctrina platónica. Documento en el que perfiló a un ser humano totalmente libre, sometido únicamente a sus propias decisiones. Libres elecciones que siempre tendrían consecuencias sobre su propia vida, para bien o para mal. Hombre en cuyo interior se halla la «chispa divina» $\mathrm{O}$ «hálito vital» con el que es capaz de influir en su propio entorno; por lo tanto, solo el hombre es responsable de su cultivo y desarrollo (Pico della Mirandola, 1486). Promulgaba igualmente la práctica de la magia natural y el hermetismo. Además, trataba de combinar la cábala con la alquimia (Priesner y Figala, 2001).

Por su parte Aristóteles, aunque había sido discípulo de Platón, estaba alejado de sus planteamientos. Cataloga al individuo como un ser racional y político, social por naturaleza. Su misión vital ya no es la reunificación con el Uno de los neoplatónicos, sino la felicidad. La política se convierte en el elemento esencial de los postulados aristotélicos, puesto que es la única capaz de conseguir la felicidad de los ciudadanos. Y corresponde al Estado promocionar la virtud de sus súbditos. La política es la ciencia del Bien y el cauce para alcanzarlo (Reale y Antiseri, 1995).

De igual modo, Aristóteles pensaba que el ciudadano ideal debía estar alejado de toda labor manual o comercial. Sus tareas tenían que centrarse en «la deliberación, la justicia, el ejército o la religión» (Touchard, 2008: 51). Y para poder dedicarse a dichas labores era necesario delegar el trabajo en los esclavos (Sandel, 2011).

El desprecio aristotélico a la actividad mercantil derivó en una Europa cristiana de dos velocidades. Una en el norte imbuida por los postulados de la Reforma y otra 
en el sur que se mantuvo fiel a la concepción de la Iglesia católica. Igualmente, los escolásticos medievales, en línea con las tesis aristotélicas, condenaron la usura. Se proscribió el cobro de interés alguno por el préstamo de dinero, lo que a todas luces perjudicó la actividad comercial (González Moreno, 2014).

Incidencia trascendental en el pensamiento escolástico medieval tuvo no solo la concepción política y económica aristotélica, sino también la moral. Aristóteles argumentaba que el poder debía estar en manos de los más virtuosos. Pues el propósito de la política se circunscribía a inculcar la virtud en sus ciudadanos, enseñarles a «llevar una vida buena». Con el fin de cumplir este objetivo se aprobarían las leyes. Por consiguiente, defiende un Estado interventor, al que se le exigía garantizar el bien común. Estado suministrador de felicidad. La individualidad es anulada por la colectividad. Porque la persona solo puede desarrollar plenamente sus facultades dentro de la sociedad, fuera de ella no es nada. Además, en la comunidad los sujetos debían ejercer aquellos puestos para los que conforme a su naturaleza estuvieran mejor preparados. Ergo, el poder institucional impide a la persona escoger por sí misma el plan de vida que se haya prefijado (Sandel, 2011). Axioma aristotélico opuesto al principio de autonomía liberal, que proscribe al Estado entrometerse en el ideal de vida individual (Martínez Zorrilla, 2009).

Pero, ¿cómo se puede estar seguro de que se haya escogido al dirigente o los dirigentes más virtuosos? Cuando se debe recordar que la Iglesia católica sepultó el concepto de armonía, la Maat egipcia. Lo que provocó que se pasara del ser al parecer. A lo que se agrega que la visión de Platón que penetró en el Imperio romano fue la idílica de la República y no la de Leyes. Es decir, ciudades que serían regidas por perfectos gobernantes y no por justos preceptos.

\subsection{La res publica christiana}

El cristianismo, con posterioridad a la caída del Imperio romano de Occidente en el 476, se erigió en su depositaria cultural frente a un nuevo mundo tribal. Una situación muy distinta a la del judaísmo, cuyos adeptos fueron expulsados de su territorio definitivamente en el 135 por el emperador Adriano. Regidor que prohibió la antigua fe monoteísta y condenó a sus practicantes al exilio, a la diáspora. Doctrina imbuida de un fuerte espíritu nacional; arraigada a un territorio concreto, Israel. Estado que los judíos solamente lograrían constituir como tal después de la Segunda Guerra Mundial.

Es más, tras la gran revuelta de los judíos contra el Imperio romano, que provocó la segunda destrucción del Templo de Jerusalén en el 70, los cristianos debían demostrar al poder establecido que no eran un peligro como los judíos. Mediante un paulatino progreso se pasó de insistir en el apocalipsis a predicar la ética que ha de 
distinguir a los fieles cristianos. Moral acorde con la filosofía estoica practicada por las clases cultas romanas, encargada de modelar al ciudadano perfecto. Así que se promulgó un rechazo a las pasiones mundanas y una vida consagrada a la virtud, en pro de honrar a Dios. Individuo que ha de someterse a los designios divinos y a las autoridades civiles, puesto que todo poder proviene del Altísimo. Sujetos centrados en la oración y en amar a todos.

Visto que el objetivo primordial de los cristianos era mantener la unión entre una comunidad vinculada por los lazos de la fe en el Mesías. Hasta que se produjese la segunda venida de Cristo, la parusía, y con ella la salvación. Tanto la de los hijos naturales de Israel, como la de los adoptivos, conforme a las tesis de la «teología de la restauración de Israel». Empero, con el tiempo se concluyó, que no solo era imprescindible convertir a cierto número de gentiles para propiciar el advenimiento de Cristo, sino que Dios deseaba que se ampliara a todos. Razón por la que la actividad misionera se instituyó como fundamental. Y como lo primordial era procurar la llegada del fin del mundo, el aspecto material no tenía relevancia, ya fuera a nivel económica o laboral. A esto hay que añadir que los postulados paulinos argumentan que lo que se salva es el grupo (Piñero 2015). Mientras que el individuo queda postergado.

Principios que comienzan ya a pergeñar una sociedad individualista en el norte de Europa, donde penetraron las corrientes esotéricas herederas del saber egipcio. En las que el conocimiento debía encontrarlo cada uno en sí mismo, por medio de la experimentación propia. Saber que se iba revelando al sujeto poco a poco, en atención a su propio esfuerzo de superación espiritual.

En cambio, en el sur de Europa emerge un enfoque colectivista, cuyo influjo arraigó en sus herederos culturales latinoamericanos. Lugares en los que impera una mentalidad comunitarista (Gargarella, 2010). Receptores mayoritariamente de la concepción paulina. Apóstol para el que la existencia del creyente solo cabe dentro de la comunidad. En la que se instruía a todos los fieles por igual. Donde los que Pablo denominó «fuertes y débiles» debían converger en un mismo punto. A saber, los más desarrollados espiritualmente se tenían que posicionar al mismo nivel que los demás, en beneficio de la unidad grupal. Renunciar a su libertad, si entraba en colisión con la fe (Piñero, 2016). Un sur de Europa y sus herederos culturales depositarios además de la teoría aristotélica de que el hombre es un ser social por naturaleza y fuera de esa sociedad no es nada. Individuo que nace y se desarrolla dentro de la congregación cristiana. Comunidad que se denominó res publica christiana y cuyos ideales se debían preservar (Turull Rubinat, 2008). Ergo, se erige un Estado interventor encargado de tutelar unos principios comunes. Sociedad comunitarista en la que quedaría justificado, por ejemplo, en pro de salvaguardar el bien del conjunto, cercenar ciertos derechos individuales. 
«Tribu» a la que el ciudadano se encuentra alienado. Necesitado de su aceptación para sentirse integrado en el grupo. Sociedades donde fácilmente irrumpen delitos como los de prevaricación. Colectivos en los que el tráfico de influencias encuentra su abono, delito que suele ser la antesala del resto (Soto Rodríguez, 2015). En definitiva, redes clientelares que emanan de este subconsciente tribal.

Lo que unido a la condena de la concepción tricotomista del individuo, por parte de la «Gran Iglesia», trajo nefastas consecuencias. La «Gran Iglesia» en el Concilio de Constantinopla IV, celebrado en el 870, equiparó el alma al espíritu (Catecismo 367). Mientras que el grupo cristiano de los gnósticos, frontalmente atacado por la ortodoxia, mantuvo la distinción entre cuerpo, alma y espíritu. Equivalente al Néfesh, Rúaj y Neshamá para los cabalistas. El Ka, el $\mathrm{Ba}$ y Ah en el Antiguo Egipto. Tricotomía recuperada en los ambientes protestantes de la teología británica y alemana durante el siglo XIX (Erickson, 2009).

De manera análoga, si para Platón y el resto de corrientes místicas el conocimiento se conseguía por medio de la introspección, Pablo condiciona su obtención gracias a la mediación de un agente externo al sujeto. Lo mismo aseverado previamente por Filón de Alejandría. La capacidad intelectiva se sustituye por la fe. Lo que deriva en que la experimentación propia, practicada por los magos del Estado egipcio para alcanzar la iluminación, queda reemplazada por la imposición del dogma al individuo, por parte de la institución eclesial. «Gran Iglesia» que concluirá por erigirse como único manantial de conocimiento (Piñero, 2015).

Y es que si el estado de iluminación en el Antiguo Egipto quedaba preservado para los magos y Platón lo acotaba a los filósofos, Pablo lo circunscribió a los creyentes en Cristo. E igual que los otros están obligados a instaurar el Bien en la sociedad. Dado que al fin y al cabo son reflejo de la fuente primigenia. Si a priori el pensamiento paulino había socializado el conocimiento al mudarlo de esotérico, reservado a unos pocos, a exotérico, promulgado a todos, pronto este sería el talón de Aquiles de la incipiente religión. Pues el proceso intelectivo y de experimentación propia quedó secuestrado por el dogma, al objeto de ejercer un férreo control sobre la comunidad. Lo que provocó el escaso desarrollo espiritual o capacidad librepensadora de los países católicos. Donde la razón quedó anulada por la fe.

Empero, el saber esotérico aduce que, en palabras de Popper, se ha de pasar de la «tribu» a la «sociedad abierta». La cábala enseña que solo al alcanzar la sefirá de la Tiferet, el individuo se encuentra liberado. Ya no depende del reconocimiento del grupo, sino que se siente completo consigo mismo. Ha logrado su máximo desarrollo como sujeto, la armonía interior. Es decir, vive según la Maat egipcia. Capaz de detectar y asumir sus fortalezas y debilidades. Despojado de todo tipo de condicionante externo. 
En consecuencia, los católicos se quedaron en la «tribu», en la sefirá de Yesod. Donde el sujeto requiere de la aceptación del grupo. Se mantiene alienado a otros, a quienes confiere poder sobre él; ergo, comete idolatría. Se asemejarían a los psíquicos de los gnósticos. En contraposición con el protestantismo. Seguidores que ascendieron a la sefirá de Tiferet. Con la adquisición de las singularidades propias de las sociedades en las que se fomentó el individualismo. Etapa existencial cuya equiparación tendería a la de los espirituales gnósticos.

Entonces, para los católicos no era necesario aprender a leer, ni escribir. Si el latín fue desplazado del uso cotidiano después de la caída del Imperio romano, la «Gran Iglesia» lo hizo su idioma oficial. Hasta el Concilio Vaticano II, que arrancó en 1962, las misas se celebraban en latín, un idioma incomprensible para el pueblo llano. Además, traducir la Biblia a la lengua vulgar fue prohibido. Si a esto se suma que la actividad evangelizadora en las zonas rurales fue escasa, la enseñanza de la doctrina se suplió por una fe exterior sometida en exceso al rito. Las procesiones, misas, ayunos servían como señas identificativas de los miembros de la comunidad y se excluía a los que no las compartían (Boeglin, 2006). Fieles que se quedaban con la envoltura del dogma, imposibilitados para adquirir una mayor asimilación de su esencia.

Por su parte los protestantes entienden que el sacerdocio lo ejerce cada individuo. Persona que se relaciona directamente con Dios, sin requerir de intermediario alguno para extraer sus particulares deducciones del libro sagrado, «el libre examen». Por lo que las escrituras debían leerse en el habla usada socialmente, de forma que los fieles pudiesen consultarlas. Bajo esta premisa Martín Lutero tradujo la Biblia al alemán. Se rechazan el culto a las reliquias o santos. Y la única muestra de fe válida es la de la propia persona ante Dios. El perdón depende directamente de cada cual, por lo que las indulgencias no tienen sentido. Misma visión mantenida por los judíos, quienes afirman que el contacto con Yahvé ha de ser directo. Sin el uso de un mediador para llegar a él, lo que se juzga como idolatría, al otorgarle un poder a esa persona sobre uno mismo en detrimento de Dios.

Norte de Europa donde se ubicarían las sociedades liberales, que pivotan sobre tres principios fundamentales. El primero corresponde al de inviolabilidad defendido por Kant. O sea, el sujeto «es un fin en sí mismo» y no puede ser utilizado en beneficio de un bien mayor. Luego está el principio de autonomía, que decreta que el Estado ha de ser imparcial respecto al plan de vida que cada cual se haya prefijado. Y por último se encuentra el principio de dignidad, que asevera que se ha de juzgar a las personas por lo que hacen y no por lo que son (Martínez Zorrilla, 2009). De forma que si fuesen políticos esto no acarrearía un mayor o menor nivel de reprobación social en cuanto a la comisión de cualquier tipo de delito. Lo que se castiga es la infracción en sí, en atención a lo detallado en el específico precepto penal. 
Axiomas liberales que se vulneran en el sur de Europa, como es el caso de España. Donde el principio de inviolabilidad se fulmina al invocar una difusa «justicia social» (Cedeira, 2017). Así como el de dignidad al dictarse hipotéticas sentencias ejemplarizantes (Codina, 2014), o al no aplicarse el llamado «derecho al olvido» en supuestos de cuestiones políticas. Lo que, unido a la visión distorsionada de la esencia humana y que provoca la divinización de la figura del político, deriva en una constante conculcación de derechos fundamentales.

\subsection{La condena al librepensamiento y al misticismo}

De manera que, por parte de la «Gran Iglesia», para evitar fisura alguna en el colectivo, se anatematizó a cualquier elemento discrepante. En una época donde el poder temporal y el espiritual estaban fusionados. Unidos por una meta común, conseguir la «confesionalización» del Estado. Sin embargo, esta unidad es rota en el norte de Europa por los movimientos reformadores. Y en el sur europeo para soslayar la atomización del Sacro Imperio romano se hace uso de la Inquisición (Martínez Millán, 2007). Institución operativa en Roma, España y Portugal. Estas dos últimas absolutamente supeditadas al poder político, modelo que exportaron a Latinoamérica y con el que controlaron el pensamiento de sus ciudadanos. Santo Oficio que igualó a masones y liberales, a los cuales condenaron (Bethencourt, 1997).

Empero, siempre hay que tener muy presente que fue la reforma gregoriana, que ambicionaba regenerar la «Gran Iglesia», la simiente que desencadenó muchos de los movimientos heréticos. Reforma de la que se sirvieron los cátaros para negar los sacramentos, en virtud de la exhortación hecha por Gregorio VII a su grey de que no los aceptaran de manos de inmorales. A saber, de aquellos clérigos que incurriesen en simonía o nicolaísmo. Con lo que el Sumo Pontífice hizo responsable al creyente de su propia vida religiosa. Argumento manejado por determinados sectores para defender una relación directa con Dios (Nathan, 1991). Reforma gregoriana que acabó por repercutir en los postulados de Lutero y producir la fragmentación de la Iglesia, que como los cátaros luchaban contra su corrupción (Piñero, 2014).

Reforma gregoriana que siguió igualmente la orden del Císter, de la que proviene tanto san Bernardo de Claraval como Joaquín de Fiore, quienes tuvieron una gran trascendencia sobre el misticismo posterior. La doctrina del primero perdió la batalla frente a la escolástica y el segundo padeció la censura de su concepción trinitaria. Lutero inició «en el protestantismo» la querencia por apelar a las creencias del abad de Claraval (Leclercq, 2017).

San Bernardo fue el artífice de la regla de los míticos templarios. Orden de caballería que asumió los ideales de la reforma gregoriana defendida por los cistercienses, unido a un recto comportamiento moral (Pastori Ramos, 2012). El abad de 
Claraval aspiraba a regenerar la «Gran Iglesia». Transformación que para él pasaba ineludiblemente por el liderazgo de los «hombres espirituales». Abanderó pues un movimiento espiritual que buscaba llegar a Dios a través de la meditación, apoyado en la oración y gracias al Amor. Un amor que comienza por uno mismo. Idéntica a la línea planteada por el judaísmo y después por las corrientes esotéricas, como la masonería.

Dado que, tal como aseguró Platón, solo el Amor conduce a la Idea suprema del Bien, a Dios. Ya que, para Bernardo, como para el resto de escuelas iniciáticas, el fin último es alcanzar la unidad con Dios, que la materia y el espíritu se disuelvan en el Absoluto. Un Dios que se halla "dentro de todo ser», por lo que no se debe buscar fuera como planteaba el exoterismo católico. Y para su entendimiento no basta con la razón, sino que se ha de acompañar de la intuición.

Una búsqueda eterna de Dios que reporta un gozo continuo. Tal como los filósofos griegos, los perennes aspirantes a adquirir la sabiduría, que conseguían la felicidad en el aprendizaje mismo. El esfuerzo constante característico de los judíos. Como el resto de corrientes místicas san Bernardo promovía la «humildad» frente al saber divino. Virtud que se contrapone a la «soberbia», fuente de todo mal. Alertó asimismo de la predisposición del ser humano al parecer y no al ser, síntoma inconfundible de la arrogancia. Persona presta a echar la culpa de sus propios fallos a los otros, sin aplicar la autocrítica exigida al objeto de mejorar.

Individuo que por su condición humana es proclive a errar, a caer en infinitud de tentaciones. Sujeto que debe ser benévolo con sus congéneres, al ser consciente de sus propias faltas. Sujeto que debe tender la mano para ayudar a los demás, fiel reflejo de cómo le gustaría ser tratado. Sujeto que siempre debe aspirar a ser justo con el prójimo y a actuar con un corazón puro. Pues, ha de buscar realizar el bien por el bien mismo y no por afán de reconocimiento alguno (Leclercq, 2017). Aptitudes personales que los masones trabajan por medio de imaginarias herramientas. Utensilios arquitectónicos con los que figuradamente embellecen su conducta (Daza, 2009).

El objetivo de san Bernardo no era una vida ajena a la sociedad, sino procurar mejorarse como persona mediante el autoconocimiento, en pro de ser provechosos para la comunidad y conseguir su progreso. Idénticos planteamientos reproducidos por los tres grados masónicos, en los que el aprendiz toma contacto con su piedra bruta. Una vez desbastada, el compañero inicia los cinco viajes para perfeccionarla y que encaje en el templo común. Mientras que el maestro se sitúa en la senda que lleva hasta al Gran Arquitecto del Universo (G.•.A.•D.•.U.•.). Cuya «chispa» divina habita en lo profundo del masón y que escenifican con la estrella flamígera, en cambio los rosacruces la encarnan en una rosa roja y los martinistas con la naturaleza crística. La Neshamá de los cabalistas (Fuentes Crespo, 1958). 
Por su parte Joaquín de Fiore fue un gran conocedor de los escritos de san Bernardo. Monje cisterciense que divide la historia en tres etapas. La primera es la Edad del Padre que correspondía al Antiguo Testamento. En la que destaca el miedo de los fieles carentes de comprensión y que asimila a los niños (Potestà, 2010) y los posiciona en régimen de esclavitud (Rucquoi, 2004). El segundo periodo es el del Hijo. Fase que coincide con la del Nuevo Testamento, con la irrupción de Cristo. Etapa dominada por los sacerdotes. Donde los fieles temen, pero ya comprenden, por eso los compara con los adolescentes (Potestà, 2010). Aquí se transforman en siervos (Rucquoi, 2004). En tanto quedaba una tercera fase, la «Edad del Espíritu Santo», en la que prevalecerán los hombres espirituales (Potestà, 2010). Periodo que se regirá por el «Evangelio eterno», el del Espíritu. Si bien, ya no se requerirá un libro propiamente, un texto en el que se esbocen "parábolas» y figuras que ayuden a captar el mensaje (Moltmann, 1984). El saber máximo será revelado gracias al Amor, por eso el sujeto alcanzará su senectud (Potestà, 2010) y conquistará su libertad (Rucquoi, 2004). Las personas no solo entenderán, sino que también amarán. En la «Edad del Espíritu Santo» el velo de los misterios se levantará. Será un pueblo sabio (Potestà, 2010).

En suma, su teoría plantea un desarrollo de la sociedad, la cual va mejorando progresivamente hasta obtener un status de plena independencia. Etapa última en la que los presbíteros ya no resultan precisos, a causa de que su existencia se vinculaba a la administración de las imágenes. Imágenes que se suprimirán al elevarse el definitivo velo y el ser humano conquistar el máximo intelecto (De Lubac, 2011). Una humanidad que renuncia a intermediario alguno para conectar con el Altísimo. Una humanidad que relega los libros sagrados o los sacramentos (Rodríguez, 2017). Porque igual que la Ley de Moisés fue superada por la Ley del Mesías, esta será aventajada por otro orden más perfecto.

Por su parte, de análoga manera al abad de Claraval, Joaquín menospreció el excesivo racionalismo de la escolástica. Escolásticos a los que llamó «maestros de la letra». En cambio, el futuro debía ser liderado por los «doctores espirituales» (Potestà, 2010). Los únicos habilitados para descifrar el conocimiento, el Daat. Tras combinar la sefirá de Biná, la razón, con la de Jojmá, la intuición.

El joaquinismo es la personal interpretación que los adeptos del abad calabrés realizaron de su tesis tripartita. Hipótesis que terminó por aclamar que «la iglesia exotérica de Pedro dejará su lugar a la iglesia esotérica de Juan, que será la de la libertad». Advenimiento del Espíritu Santo que algunos atisbaron con la irrupción del Renacimiento y los movimientos reformadores. Hay que tener presente que gran parte de las corrientes masónicas y martinistas presiden sus reuniones con la Biblia abierta precisamente por el Evangelio de san Juan.

El joaquinismo tuvo un gran influjo sobre Jacob Böhme. Místico protestante a quien Louis Claude de Saint Martin, figura clave del martinismo, denominó «el prín- 
cipe de los filósofos divinos». También se detecta el joaquinismo sobre los rosacruces y la masonería. Así como en el idealismo alemán, especialmente en Hegel y Schelling (De Lubac, 2011).

Las tesis de Jacob Böhme se infiltraron en el pietismo (Rocha Barco, 1993). Corriente protestante que rechazaba el excesivo racionalismo y abogaba por la espiritualidad experiencial, enfocada en potenciar la caridad y honestidad de su feligresía. Pietismo con el que tuvo relación Kant desde su infancia a través de su núcleo familiar, creador de la teoría del «imperativo categórico» moral. Axioma por medio del cual el sujeto se imponía no mentir bajo ningún concepto, o sea, cumplir siempre el mandato de Maat. Un ser humano para Kant no solo racional, sino también emocional. Filósofo que fue un defensor a ultranza de la libertad, para quien el individuo jamás podía ser utilizado por el resto en beneficio de un supuesto bien superior comunal. Ergo, se oponía a cualquier tipo de utilitarismo, ideología que subordina la toma de decisiones a obtener la satisfacción de la mayoría. Sin importarle sacrificar a alguien o a unos pocos si con eso incrementa el placer de muchos. Su idea de justicia, pues, parte de la maximización del bienestar de la sociedad. Entretanto la idea de justicia de Kant pivota sobre la libertad.

Utilitarismo en el que se cae cuando se habla de «condenas ejemplarizantes» o se alude a una «supuesta justicia social». Inclusive cuando se exigen dimisiones sin una sentencia judicial, después de que «las condenas de telediario» pulvericen la presunción de inocencia. En consecuencia, se obvia también el derecho inalienable de igualdad ante la ley. Decisiones encaminadas a saciar los deseos de la «tribu»; pero contrarias a los principios fundamentales sobre los que se erigió el Estado Liberal.

Para Kant la virtud o moral debían provenir de las reglas que se diese la persona a sí misma. Reglas que el individuo tiene la obligación de cumplir, no porque se las hayan impuesto externamente, sino para ser coherente con sus propias convicciones. De manera tal que era contrario a la postura aristotélica de que debiese ser el Estado el encargado de promover la virtud. Planteamientos kantianos veneradas por el idealismo alemán (Sandel, 2011) y en cuyo sustrato se atisban conceptos provenientes del Corpus Hermeticum (Pele, 2015).

Sin embargo, toda corriente espiritual que emergía era sofocada por la «Gran Iglesia». Al considerarlas como un peligro para su subsistencia. Tras creer detectar por parte de estos grupos el presunto objetivo joaquinita de acabar con «la iglesia exotérica de Pedro», la institucional; para luego instaurar la «esotérica de Juan», presidida por el Espíritu, la libertad.

Así que en el norte europeo a partir del mito de la estrella flamígera por parte de los masones o la rosa roja del pensamiento rosacruz proliferaron las logias. A saber, el hálito vital insuflado por la divinidad, el espíritu, la parte más elevada del 
ser humano. Escuelas donde se formarían los ciudadanos que llegarían a ostentar altas cotas de poder. Lugares donde se les enseñaban los pilares fundamentales de las democracias liberales y se les instaba a procurar su avance. Centros en los que se instruía a los grados superiores para que combatieran la concentración de poder en manos de unos pocos, por muy virtuosos que estos fuesen (Álvarez Lázaro, 2012).

Y es que fue precisamente un masón el autor de la teoría de la separación de poderes más divulgada, la de Montesquieu. Iniciado el 12 de mayo de 1730 en la logia londinense Horn. Artífice de la idea de los «contrapesos». Donde el poder ejecutivo, el legislativo y el judicial se controlan entre sí, sin adquirir primacía ninguno de estos poderes estatales sobre el resto. De forma tal que teóricamente se mantiene un «equilibrio» entre el legislativo y el ejecutivo, además de garantizarse la independencia del judicial.

Pues Montesquieu era plenamente consciente de la imperfección de todo ser humano (Alvarado Planas, 2017). Individuo que, por más que se esmere, será un mero aprendiz a lo largo de toda su existencia. En suma, el filósofo, el eterno aspirante a conseguir la sabiduría. Pues para los griegos únicamente a los egipcios se podía llamar sabios. La humildad ante el saber infinito por la que abogaba la tradición, el talmid jajam de la cábala, la docta ignorancia de Nicolás de Cusa. Así que los masones asumen que siempre serán aprendices. Mientras que los rosacruces nunca se declaran como tal, al tener muy presentes sus limitaciones como humanos. Lo que choca con la teoría del «rey-filósofo» de Platón y que penetró en el Imperio romano para consolidarse en los territorios católicos. Presunción arrogante y pueril de que puede haber alguien que lo sepa todo.

En tanto en los países católicos, en un determinado momento, se sustituyó a la religión por el Estado. Se va de un Estado confesional a otro aconfesional, pero con las mismas connotaciones. Se concibe como una virtud la juventud y se concluye que el ideal de regeneración pasa por reducir la edad de los líderes. Cuando a lo largo de la historia se escogía como jefe del grupo a los más ancianos, al que poseía una larga experiencia vital (Negro, 2009). Y ya advertía la Biblia sobre las consecuencias de esta inadecuada opción: «Yo les daré por jefes a adolescentes, y niños caprichosos los dominarán» (Isaías 3, 4).

\section{Conclusiones}

A causa de la herencia religiosa y filosófica en las naciones católicas el político es reputado como un prohombre y como tal no cabe que yerre. Concepción mesiánica que produce una constante violación de derechos fundamentales, a la hora de intentar reducir los casos de corrupción. En cambio, los de raíz protestante se centran en 
trabajar sobre las modificaciones del sistema y en aumentar las medidas de control, como línea preventiva para que no se dé la acción corrupta. Ya que tienen clara la imperfección y debilidad humana.

\section{Bibliografía}

ALBAR et al. (1995). Cristianismo primitivo y religiones mistéricas, p. 230, Madrid: Ediciones Cátedra.

ALMENDRO, M. (2010). Chamanismo. La vía de la mente nativa (Edición digital), Barcelona: Editorial Kairós.

ALVARADO PLANAS, J. (2017). Monarcas masones y otros príncipes de la acacia, Vol. I, pp. 189-191, Madrid: Dykinson.

ÁlVAREZ LÁZARO, P. (2012). La masonería, escuela de formación del ciudadano. La educación interna de los masones españoles en el último tercio del siglo XIX (Cuarta edición), Madrid: Publicaciones de la Universidad Pontificia Comillas.

ÁLVAREZ-RENDUELES, J.R. -selección y estudio introductorio preliminar- (2014). El cálculo del consenso. Escritos escogidos, p. XXI, Pamplona: Editorial Aranzadi, S.A.

BETHENCOURT, F. (1997). La Inquisición en la época moderna: España, Portugal, Italia, siglos XV-XIX, Madrid: Ediciones Akal.

BOEGLIN, M. (2006). "Luteranos franceses en la España de los Austrias. Aspectos culturales de un conflicto religioso", en Bruña Cuevas, M.; de Gracia Caballos Bejano, M.; Illanes Ortega, I.; Ramírez Gómez, C. y Raventós Barangé, A. (Coordinadores), La cultura del otro: español en Francia, francés en España, pp. 118-132, Sevilla: Universidad de Sevilla. Disponible en: https://dialnet.unirioja. es/servlet/articulo?codigo=4047107 [Consulta: 10 de diciembre de 2018]

CASTEL, E. (2001). Gran diccionario de mitología egipcia, Madrid: Alderabán Ediciones.

CEDEIRA, B. (2017, 3 de marzo). "La defensa de 'El Bigotes' recurre la "justicia social" del fiscal para mantenerle en prisión". El Español.

CODINA, E. (2014, 8 de noviembre). "Una sentencia ejemplarizante”. El País.

COSTA, J. (1902). Oligarquía y caciquismo como la forma actual de gobierno en España: urgencia y modo de cambiarla, Madrid: Imprenta de los hijos de M.G. Hernández.

DAZA, J. C. (2009). Diccionario Akal de la Francmasonería, Madrid: Ediciones Akal (Obra original publicada en 1997).

DE LUBAC, H. (2011). La posteridad espiritual de Joaquín de Fiore. I. De Joaquín a Schelling (Segunda edición), Madrid: Ediciones Encuentro (Obra original publicada en 1981). 
DE LUBAC, H. (2011). La posteridad espiritual de Joaquín de Fiore. II. De Saint-Simon a nuestros días (Segunda edición), Madrid: Ediciones Encuentro (Obra original publicada en 1981).

DEUSDAS AYALA, M. B. (2001). El carisma político en la teoría sociológica. [Tesis doctoral]. Universitat de Barcelona, Teoria Sociològica, Filosofia del Dret i Metodologia de les Ciències Socials, España. Disponible en: http://hdl.handle. net/10803/2962 [Consulta: 10 de diciembre de 2018]

DULITZKY, J. (2011). Akenatón. El faraón olvidado, Buenos Aires: Editorial Lectorum.

ERICKSON, M. (2009). Teología Sistemática, Barcelona: Editorial CLIE.

FINKELSTEIN, I. y SILBERMAN, N. (2003). La Biblia Desenterrada, Madrid: SIGLO XXI DE ESPAÑA EDITORES, S.A.

FREUD, S. (1991). Obras completas. Sigmund Freud. Volumen 23 (1937-39), p. 24 (Segunda reimpresión), Buenos Aires: Amorrortu editores.

FUENTES CRESPO, P. (1958). "El conocimiento místico en san Bernardo de Claraval”. Revista de Espiritualidad, Vol. 17 (n 69), pp. 533-550. Disponible en: http://www.revistadeespiritualidad.com/upload/pdf/934articulo.pdf [Consulta: 10 de diciembre de 2018]

FUENTES CRESPO, P. (1958). "El conocimiento místico en san Bernardo de Claraval”. Revista de Espiritualidad, Vol. 17 (n ${ }^{\circ}$ 66), pp. 5-32. Disponible en: http://www.revistadeespiritualidad.com/upload/pdf/933articulo.pdf [Consulta: 10 de diciembre de 2018]

GARGARELLA, R. (2010). Las teorías de la justicia después de Rawls. Un breve manual de filosofía política, pp. 125-132 (5ª impresión), Madrid: Espasa Libros.

GIL, L. (2004). Therapeia. La medicina popular en el mundo clásico, p. 297, Madrid: Editorial Triacastela (Obra original publicada en 1969).

GONZÁLEZ MORENO, M. (2014). "Líneas maestras del ideario de la escolástica (y II): comercio, cambios y usura”. eXtoikos, (no 14). Disponible en: http://www. extoikos.es/n14/pdf/12.pdf [Consulta: 10 de diciembre de 2018]

LECLERCK, J. (2017). San Bernardo y el espíritu cisterciense, Burgos: Grupo Editorial Fonte.

LUDUEÑA ROMANDINI, F.J. (2006). Homo oeconomicus: Marsilio Ficino, la teología y los misterios paganos, Madrid: Miño y Dávila editores.

MARTÍN VALENTÍN, F. (2002). Los magos del Antiguo Egipto, Madrid: OBERON (Grupo Anaya).

MARTÍNEZ MILLÁN, J. (2007). La Inquisición española, Madrid: Alianza Editorial. 
MARTÍNEZ ZORRILLA, D. (2009). "Módulo 2: Los fundamentos teóricos de los derechos humanos”, pp. 11-15. En Sánchez Sánchez, V.M. y Bonet Pérez, J. (Coordinadores), Derechos humanos (Tercera edición), Barcelona: FUOC.

MEIER, K. y HOLBROOK, T. (1992). "I Seen My Opportunities and I Took Em: Political Corruption in the American States". The Journal of Politics, Vol. 54, No. 1, pp. 135-155. The University of Chicago Press. Disponible en: https://www. jstor.org/stable/2131647?seq=1\#page_scan_tab_contents [Consulta: 19 de junio de 2018]

MELIÁN, I. (2015). La corrupción en España y sus causas. Createspace Independent Publishing Platform

MOLTMANN, J. (1984). “La esperanza cristiana: ¿mesiánica o trascendente?”. Selecciones de teología, (no 90). Disponible en: http://www.seleccionesdeteologia. net/selecciones/llib/vol23/90/090_moltmann.pdf [Consulta: 10 de diciembre de 2018]

NATHAN, E. (1991). "Herejía y cultura popular en la Edad Media”. Utopías. Revista de la Facultad de Filosofía y Letras de la UNAM, núm. 8, pp.2-7. Disponible en: http://hdl.handle.net/10391/5713 [Consulta: 10 de diciembre de 2018]

NEGRO, D. (2009). El mito del hombre nuevo, Madrid: Ediciones Encuentro, S.A.

OÑATE ZUBÍA, M. T. y ZAMORA CALVO, J.M. (2013). “Timeo: El mito de Platón y la creación científica del mundo”. UNED. Disponible en: https://www.youtube. com/watch?v=tVhBEpnjg0Q [Consulta: 10 de diciembre de 2018]

ORTEGA (2016, 5 de junio). “La filosofía del Renacimiento”. Breve manual de filosofía. Disponible en: https://youtu.be/-ktgwCFrI4A [Consulta: 10 de diciembre de 2018]

PASTORI RAMOS, A.A. (2012). Bernardo de Claraval y la idea de guerra santa. [Tesis doctoral]. Universidad de Buenos Aires, Facultad de Filosofía y Letras, Argentina. Disponible en: http://www.academia.edu/2002364/Bernardo_de_ Claraval_y_la_idea_de_guerra_santa [Consulta: 10 de diciembre de 2018]

PELE, A. (2015). "Kant y la Dignidad Humana". Revista Brasileira de Estudios Políticos, $\mathrm{n}^{\circ}$. 111, pp 15-46. Disponible en: https://www.researchgate.net/ publication/299651701_KANT_Y_LA_DIGNIDAD_HUMANA [Consulta: 10 de diciembre de 2018]

PÉREZ PARIENTE, J. (2016). ¿Qué sabemos de? La alquimia, Madrid: CSIC-Catara. PICO DELLA MIRANDOLA, G. (1486). "Discurso sobre la dignidad del hombre". Revista digital universitaria, Vol. 11, no 11 (2010). Disponible en: http://www. revista.unam.mx/vol.11/num11/art102/art102.pdf [Consulta: 10 de diciembre de 2018] 
PIÑERO, A. (2008). Año I. Israel y su mundo cuando nació Jesús, Madrid: Ediciones Laberinto.

PIÑERO, A. (2014). Los cristianismos derrotados. ¿Cuál fue el pensamiento de los primeros cristianos heréticos y heterodoxos? (5a edición), Madrid: Editorial EDAF.

PIÑERO, A. (2015). Guía para entender a Pablo de Tarso. Una interpretación del pensamiento paulino, Madrid: Editorial Trotta.

PIÑERO, A. (2016). Guía para entender el Nuevo Testamento, Madrid: Editorial Trotta.

PIULATS RIU, O. (2010). Egiptosophia. Relectura del mito al logos (Edición digital), Barcelona: Editorial Kairós.

POTESTÀ, G. L. (2010). El tiempo del Apocalipsis. Vida de Joaquín de Fiore, Madrid: Editorial Trotta (Obra original publicada en 2004).

PRIESNER, C. y FIGALA, K. -Editores- (2001). Alquimia. Enciclopedia de una ciencia hermética, pp. 375-376, Barcelona: Herder. (Obra original publicada en 1998).

PUNSET, E. (2006, 30 de noviembre). "El alma está en el cerebro". El Cultural.es. Disponible en: http://www.elcultural.com/revista/letras/El-alma-esta-en-elcerebro/19194 [Consulta: 10 de diciembre de 2018]

RAMOS JURADO, E.A. (2007). De Platón a los neoplatónicos: escritura y pensamiento griegos, Madrid: Editorial Síntesis.

RAND, A. (2006). La virtud del egoísmo, Buenos Aires: Grito Sagrado Editorial (Obra original publicada en 1964).

REALE, G. y ANTISERI, D. (1995). Historia del pensamiento filosófico y científico. Tomo Primero. Antigüedad y Edad Media, Barcelona: Editorial Herder.

REBISSE, C. (2015). Historia y Misterios de los Rosacruces (Edición Electrónica), Barcelona: Ediciones Rosacruces.

ROCHA BARCO, T. (1993). "Un apunte sobre la teoría de la historia del lenguaje: Böhme, Saint-Martin y Kleuker”. Anuario de estudios filológicos, Vol. 16, págs.351366. Disponible en: https://dialnet.unirioja.es/servlet/articulo? codigo $=58797$ [Consulta: 10 de diciembre de 2018]

RODRÍGUEZ, V. (2017). “Joaquín de Fiore: La Edad del Espíritu”. Estudios Públicos, (no 145), pp.191-204. Disponible en: https://www.cepchile.cl/joaquin-de-fiorela-edad-del-espiritu/cep/2017-04-21/104735.html [Consulta: 10 de diciembre de 2018]

RUCQUOI, A. (2004). "No hay mal que por bien no venga. Joaquín de Fiore y las esperanzas milenaristas a fines de la Edad Media”. Clío \& Crímen: Revista del Centro de Historia del Crimen de Durango, (no 1), pp. 217-240. Disponible en: https://dialnet.unirioja.es/servlet/articulo? codigo=1104262 [Consulta: 10 de diciembre de 2018] 
SABAN, M. (2012). El misterio de la creación y el árbol de la vida en la mística judía: una interpretación del Maasé Bereshit. [Tesis doctoral]. Universitat Rovira i Virgili, Departament d'Antropologia, Filosofia i Treball Social, España. Disponible en: http://hdl.handle.net/10803/96298 [Consulta: 10 de diciembre de 2018]

SABAN, M. (2016). La cábala. La psicología del pensamiento, Barcelona: Editorial Kairós.

SANDEL, J. (2011). Justicia. ¿Hacemos lo que debemos?, pp. 209-235, Barcelona: DEBATE.

SOTO RODRÍGUEZ, M.L. (26 de febrero de 2015). "El delito de tráfico de influencias en la Administración pública”. Diario La Ley, No 8489, Sección Doctrina, Ref. D-72 (LA LEY 1249/2015), Madrid: Editorial LA LEY.

SUÁREZ CÓRDOBA, I. (2015, 31 de julio). "Zoroastrismo, arios, judaísmo y religión". Las 2 orillas. Disponible en: https://www.las2orillas.co/zoroastrismoarios-judaismo-religion/ [Consulta: 10 de diciembre de 2018]

TOUCHARD, J. (2008). Historia de las ideas politicas (6 edición, 2a reimpresión), Madrid: Editorial Tecnos (Obra original publicada en 1961).

TREISMAN, D. (2000). “The causes of corruption: a cross-national study”. Journal of Public Economics (76), pp. 399-457. Disponible en: https://www.amherst.edu/ media/view/131389/original/Treisman2000.pdf [Consulta: 19 de junio de 2018]

TURULL RUBINAT, M. (2008). Fundamentos históricos del derecho, Barcelona: FUOC.

YATES, F. (2008). El iluminismo rosacruz, Madrid: Ediciones Siruela (Obra original publicada en 1972). 
